\title{
A Study into Medical Wastage of Recruits
}

\author{
Capt Sir Richard H Lynch-Blosse Bt \\ MBBS, MRCGP, RAMC \\ * Army Personnel Selection Centre
}

SUMMARY: The discharge for medical reasons of recruits in the first five months of 1984 was studied. The rate of $\vec{\Rightarrow}$ discharge for medical reasons was found to be $3.3 \%$ of the total intake for the same period. Many recruits were $\stackrel{\oplus}{?}$ discharged without appearing before a medical board. The number of medically discharged recruits represents $12.4 \%$ of $q$ the total discharges for all reasons.

The conditions giving rise to discharge were investigated and it was found that most were related to lower limb problems, particularly patellofemoral pain.

Suggestions are made as to ways of decreasing the medical wastage, but it is thought to be unlikely that much impact in would be made on the low rate of $3.3 \%$

\section{Introduction}

There always seems to be concern about the number of discharges of recruits from the various training units, especially those discharged for medical reasons. A search of the medical literature has revealed no papers on the subject, and as far as I am aware there has never been a published army-wide survey of the problem. Thus it appears that the concern is not really based on any hard facts.

In the light of this it was decided to set up a study of recruits who passed through the Army Personnel Selection Centre (APSC) at Sutton Coldfield before going to Basic Training Units, and who were subsequently discharged on medical grounds, to provide a base line of information. This initial study lasted for five months at the beginning of 1984 , and has been followed by a continuous audit of discharges. Such audit is able to provide accurate information quickly on demand, and this is often required by both the Army Recruiting Directorate and the Army Medical Directorate.

The APSC seemed to be the logical centre for the study, as all discharges are notified here on Army Form B 6863 (Notification of Discharge of a Regular Recruit). This document contains the identity of the recruit, his Depot, which Careers Information Office he attended, dates of joining unit and being discharged, medical grades on entry and discharge, a brief history of the case, and reference to the paragraph of Queens Regulations under which he was discharged.

APSC Sutton Coldfield selects male adults, young soldiers and juniors from England, Ireland and Wales. Most of the Scottish recruits are selected through the Scottish wing and so were not included in the study.

\section{Methods}

The AFs B 6863 received by APSC were sorted initially by the $\mathrm{OC}$ of the Selection Wing. All those discharged for medical reasons as stated in Para 3 of the

\section{* The Surgery, Clifton Hampden, Nr Abingdon, Oxon}

AF B 6863 (Brief History of the Case) were sent to the Medical Officer.

In the majority of cases it was not clear exactly why the recruit had been discharged, and so a request was then sent to the relevant Manning and Record Office asking for copies of the medical documents concerning the individual. In most cases this request led to the production of the necessary material.

The information required was extracted from these documents and then loaded onto a commercial filing and sorting program (VU FILE) on a personal micro- T1 computer (ZX Spectrum). This greatly speeded up the processing of data on completion of the study.

Results

The total number of enlistments for the recruiting year 1 April 1983 to 31 March 1984 is shown at Table 1:

\section{Table 1}

\begin{tabular}{lr}
\hline Adults & 12,474 \\
Juniors & 6,768 \\
Womens Services & 1,376 \\
\hline
\end{tabular}

Those passing through APSC are shown in Table 2:

Table 2

\begin{tabular}{lr}
\hline Adults & 11,726 \\
Juniors* & 2,552 \\
\hline
\end{tabular}

Footnote to Table 2 - the number of juniors is small because their recruiting has only recently been centralized at APSC.

The wastage of those applicants who are considered by ACIOs to be serious applicants is shown in Table 3: 
Table 3

\begin{tabular}{lr}
\hline During Recruiting Process & $\%$ \\
\hline Withdrawn/Rejected at ACIO & 60 \\
$\quad$ (of which 6\% are medical rejections) \\
Rejected at APSC & 6 \\
Fail to enlist after acceptance & 1 \\
Balance enlisted & 33 \\
\hline
\end{tabular}

\section{During Basic Training}

Of those enlisted $24 \%$ fail to complete basic training.

From Table 3 it can be seen that only about 1 in 4 serious applicants at ACIO level eventually proceed to join a service unit from their Basic Training Units.

In $1982 / 83$ of 8,669 recruits enlisted, $0.1 \%$ were discharged on formal medical grounds. However the majority of discharges for medical reasons are effected through Queens Regulations as "defects in enlistment", "not finally approved" or "at recruits request, free or on payment". Many of these do not appear before formal medical boards but are assessed as below Enlistment standard though within the Employment Standard at
Initial Pulheems. The true rate of discharges for medical reasons is thought to be the region of $4 \%$ of the total intake or $15 \%$ of the total wastage in training.

The number of recruits enlisted through APSC during the period studied is shown in Table 4:

Table 4

Adults \& Young Soldiers

Juniors

Total

The total number of discharges for medical reasons notified in that period, 1 January 1984 to 31 May 1984, was 208 . This represents $12.4 \%$ of the 1682 discharges notified in the same period or $3.3 \%$ of the total intake. The number actually appearing as Medical Discharges in the statistics for the same period was 4 , that is $0.2 \%$ of the discharges or $0.06 \%$ of the total intake.

The discharges were classified under the PULHEEMS system and also by way of "culpability" ie: where fault had arisen resulting in failure to complete basic training (Table 5).

Table 5

Disabilities resulting in discharge classified by PULHEEMS and categories identified in Table 1

\begin{tabular}{|c|c|c|c|c|c|}
\hline $\mathbf{P}$ & $\mathbf{a}$ & $\mathbf{b}$ & c & d & Totals \\
\hline Acne & & & & 2 & 2 \\
\hline Asthma & 4 & & 7 & & 11 \\
\hline Cardiovascular & & & 2 & 1 & 3 \\
\hline Dental Caries & & & & 1 & 1 \\
\hline Diabetes & & 1 & & & 1 \\
\hline Eczema & & & 2 & 1 & 3 \\
\hline Epilepsy/Dizziness/ & & & & & \\
\hline Blackouts & 6 & & 1 & & 7 \\
\hline Epistaxis & 1 & & & & 1 \\
\hline Headaches/Migraines & 5 & & 2 & & 7 \\
\hline Nausea & 1 & 1 & & & 2 \\
\hline Peptic ulcer/Dyspepsia & 2 & 1 & & & 3 \\
\hline Piles & & & 1 & & 1 \\
\hline Post Operative Pain in & & & & & \\
\hline Scar & 1 & 1 & & & 2 \\
\hline Stamina Lacking & 3 & & & & 3 \\
\hline TOTAL P & 23 & 4 & 15 & 5 & 47 \\
\hline
\end{tabular}

U

Pain Following

Fractures

Recurrent Shoulder

Dislocation

1

2

3

Shoulder Strain

TOTAL U

1

4

1

2

7


Table 5 continued

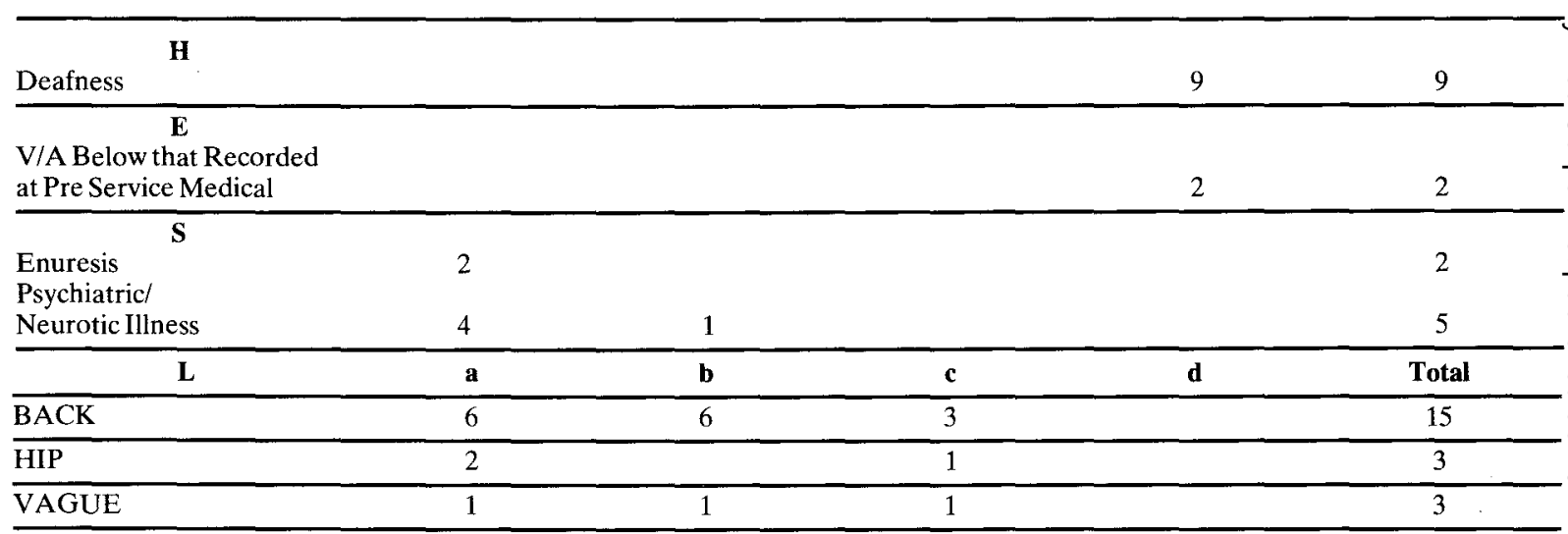

KNEE

a. Chondromalacia

Patellae/Patellofemoral

Pain

b. Torn Meniscus

c. Osgood Schlatters

d. Bakers cysts recurring

e. Unspecified

$3 \quad 1$

ANKLES

3

\section{FEET}

a. Pes Planus/

Painful Feet

b. Pes Cavus/

Deformed or scarred feet

1

1

$43 \quad 7$

73

1

OLD FRACTURES

Giving rise to pain

a. Leg/Femur

b. Knee

1 5

122

1

2

4

6
b. Knee

c. Ankle/foot

TOTAL L

Total of all sections of PULHEEMS

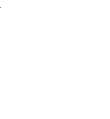

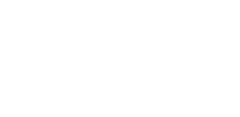

2

1

Footnote to Table 5

Source of fault resulting in failure to complete basic training

a. Concealment or failure to declare defect by recruit.

b. Defect developing during training.

c. Defect noted at Pre Service Medical but thought to be worth a try.

d. Defect missed at Pre Service Medical.

\section{Discussion}

Although the study is quite small numerically, and covers a period of only five months at the beginning of 1984 , it is felt that it reflects the average picture of medical discharges in the Army.

An inherent fault in the study is that some of the recruits discharged during the period studied were recruited prior to the study commencing, and likewise some recruited during the study period were discharged later. It would have been more accurate to follow, say, a $\frac{D}{0}$ six month cohort of recruits through to the end of their basic training; available time however precluded this $N$ approach.

Another source of error is the reliance on the system 
of AFs B 6863 reaching their appropriate destinations. In one case it was discovered that these notifications were not sent to APSC and so they do not appear in the results.

As was expected, most of the discharges were under the ' $L$ ' quality of PULHEEMS $(65 \%)$ and over $50 \%$ of these were for patellofemoral pain or clinically diagnosed chondromalacia patellae $(35 \%$ of total numbers).

Part of the purpose of the study was to identify areas which could be "tightened up". Those conditions which were concealed by the recruit (Table 5, category (a)) and revealed subsequently during training are likely to continue to be concealed by future recruits despite warnings of the consequences of this at APSC. In the case of knee problems the recruit was often blamed for concealing a condition if he happened to mention a past history of knee trouble to his RMO when there was no indication of this on his F Med 1. It is suspected, however, that a number of these complaints were revealed to the doctor performing the pre-service medical, but not recorded as they appeared to have healed or were not considered significant.

The most worrying concealments are probably asthma, epilepsy and psychiatric illness which account for $16(7.6 \%)$ of the total medical discharges.

Of those conditions developing subsequently (Table 5 , category (b)), the greatest number were attributable to lower limb or back injuries $(89 \%$ of the total in category (b)). Forty three of these were made up jointly of chondromalacia patellae or patellofemoral pain, and could possibly be prevented by modifying training programmes.

Those conditions noted on the F Med 1 (Table 5, 요 category (c)) but thought to be "worth a try" accounted $\Omega$ for $24 \%$ of the total. It would be difficult to stop recruiting these individuals without losing a great many recruits with similar past histories, but who successfully complete basic training and become soldiers. It is often only by testing the soldier in training that the particular weakness is revealed. Thus the fractured ankle that appears to have healed well and has given no trouble in civilian life for five years may become painful within 2-3 weeks of commencing training, or the asthma that seems to have disappeared and on which lung function tests are normal suddenly returns on starting training.

The conditions that are missed at pre-service medical (Table 5 , category d) accounted for $11 \%$ of the medical discharges (1.4\% of all discharges) and over one third of these were due to audiometry not being available at some ACIOs (a situation which is being improved). The rest were either missed or ignored by the examining doctors, and the only way of improving this very small number is by encouraging more careful examinations.

A factor which may have a bearing on categories (e and (d) is that in 1982 it was decided to disestablish atf full time CMP posts at ACIOs and replace them sessional GPs. Some of these are ex-forces, but mang have had no contact with the Army prior to being appointed. It would be worthwhile encouraging these

Table 6

Intake and discharge by ARM \& Corps

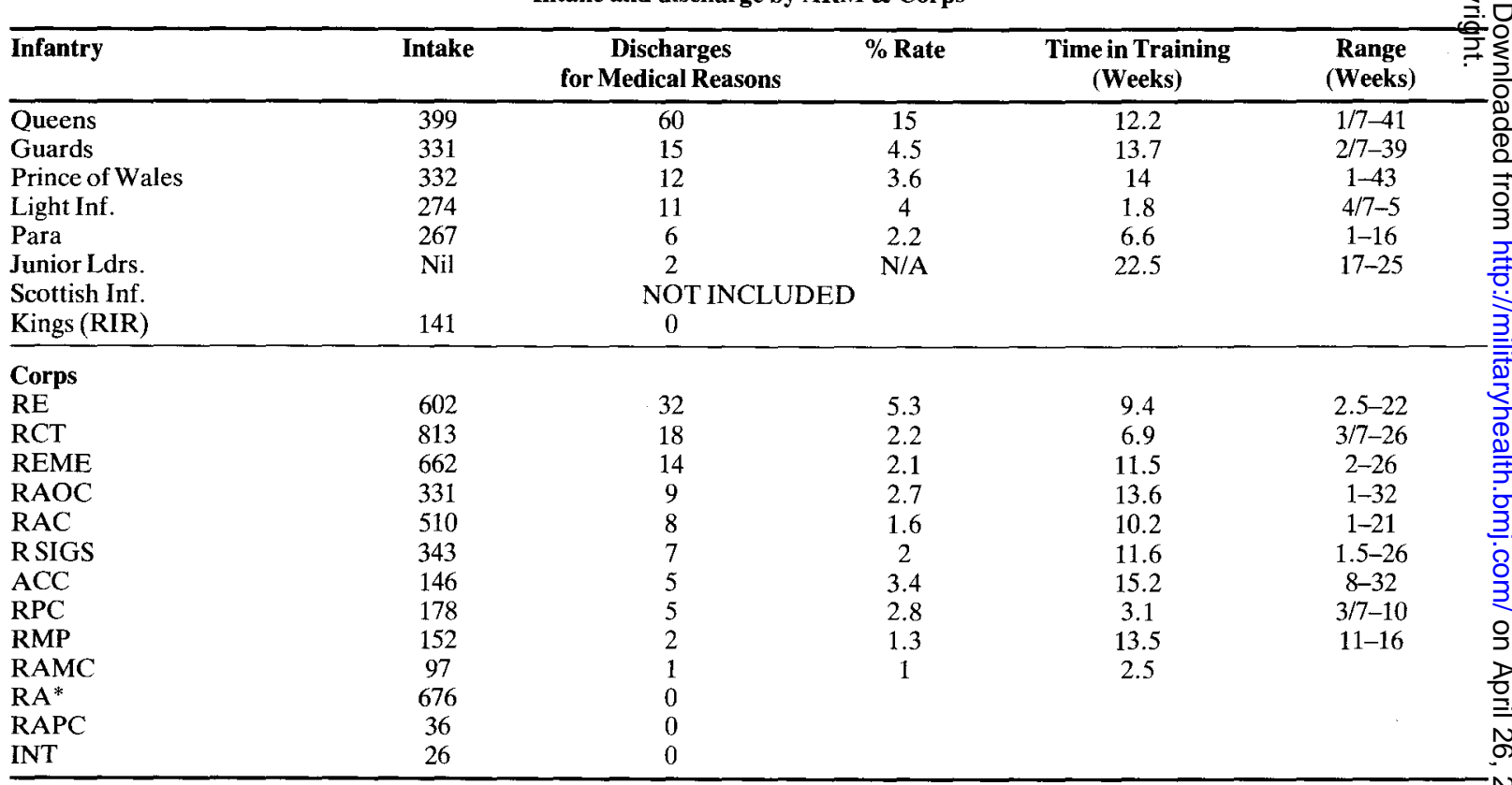

* The RA's low figure is due to their not returning AF B6863/s to APSC. In fact they discharged 7 for medical reasons out of a total of 98 . 
doctors to attend the courses of instruction on the PULHEEMS system which are conducted at the Royal Army Medical College. This would improve their understanding of the particular problems associated with life as a recruit in the army and why certain conditions are incompatible with army life.

The number of discharges by depots (Table 6) was between $1 \%$ and $6 \%$ for all but one depot which discharged $15 \%$ of its intake medically. Of these $82 \%$ were under the ' $L$ ' quality and $61 \%$ of these (or $50 \%$ of total) were for knee conditions, as compared with $65 \%$ and $63 \%$ ( $41 \%$ of total) respectively for the whole study. This would appear to indicate a higher rate of knee and lower limb injuries which might be reduced by altering training schedules.

This high rate of discharges from the Queens Division distorted the figures for the ACIO districts (Table 7) as this division recruits mainly from London, SE and Eastern Districts. It also accounted for 22 of the 52 discharges in Eastern District.

The amount of time spent in training before discharge (Table 6) varied widely between different depots. This probably reflects a difference in tolerance of injuries in different units. Those that were identified as juniors at AF B6863 tended to stay in the service for longer before being discharged, and were repeatedly "backsquadded". In one case the recruit spent 43 weeks at the depot before being discharged.

The infantry tended to discharge the highest number in the first 4 weeks (over $60 \%$ of these in the first two weeks) and this rate gradually tailed off up to 10 months (Fig. 1). The discharge rate for the other units was fairly constant, rising slightly after three months, then dropping rapidly and being fairly constant from 4-8 months onwards.

The causes of medical discharge in the first two weeks of training (41 of the total) are mostly those defects that have been missed at initial examination together with those that have been noted, but where the RMO does not consider that it is safe or worthwhile to test the recruit in training. There are also a few cases of concealment that become evident very quickly.
The figures produced in this study agree roughly with the generally accepted figures provided by DMSD/ EMR. The wastage rate due to medical discharges was $0.06 \%$ of the total intake of the 6,316 recruits included in this study. The true rate, including those medical discharges that appear as "defects in enlistment", etc. is $3.3 \%$ of the total intake. This should be compared with the total wastage during that period which was $26.6 \%$. The true rate of medical discharge is lower than is generally suspected.

\section{Conclusion}

There may well still be concern about the supposed high rates of discharge of recruits for medical reasons, but as this represents only one eighth of the total number of discharges for all reasons and between 3 and $4 \%$ of the total intake, it is difficult to see how the medical services can make much impact on wastage rates.

Careful history-taking at pre-service medical examination by the medical practitioner himself may elicit more conditions that at present appear as concealments. In a random sample of $200 \mathrm{Fs}$ Med 1 reviewed at APSC, the medical history was either filled in by the applicant himself or an assistant in $30 \%$ व्ष cases. In particular, applicants should be questione 8 closely about asthma, epilepsy and psychiatric history. $\square-$

If a condition that may affect the potential recruit $\$$ performance in training is elicited, it should be assessed most carefully, and referral made for specialist opiniog if there is doubt.

Recruits with suspected ear disease should always $\overrightarrow{0}$ have audiometric assessment before being sent fe्ष selection.

Modification of the training schedules may influence the high numbers of lower limb injuries, particularly patellofemoral pain and chondromalacia patellae. Physical training should allow sufficient time for recovery. Exercise certainly stimulates improvement in muscular strength and efficiency, and in cardiovascular efficiency, but these effects occur in the resting phase after exercise. Over stimulation produces injury in many cases. Additionally, a recent leader in the $\mathbf{B M J}^{1}$

Table 7

Number of recruitments and discharges by recruiting District

\begin{tabular}{|c|c|c|c|}
\hline District & Number Recruited & Medically Discharged & $\begin{array}{l}\text { Medical Discharge } \\
\text { as \% of Recruits }\end{array}$ \\
\hline London & 338 & 17 & $5 \%$ \\
\hline Eastern & 819 & 52 & $6.3 \%$ \\
\hline S.E. & 767 & 28 & $3.7 \%$ \\
\hline S.W. & 485 & 25 & $5.2 \%$ \\
\hline West \& Wales & 933 & 25 & $2.7 \%$ \\
\hline N.W. & 871 & 26 & $3 \%$ \\
\hline N.E. & 926 & 31 & $3.4 \%$ \\
\hline Scotland* & 1 & 3 & 1 \\
\hline N. Ireland & 147 & 2 & $1.4 \%$ \\
\hline
\end{tabular}


confirms the supposed therapeutic and anabolic effects of sleep and this should be brought to the attention of all those involved in training.

Another paper ${ }^{2}$ in the Journal of the Royal Army Medical Corps has shown that $75 \%$ of those recruits presenting with patellofemoral pain can be cured and complete basic training following simple treatment over a two month period. However those with a pre-service history of such pain of insidious onset have a much reduced chance of cure compared with those of acute traumatic origin, and such a history if elicited should give rise to concern.
Centralized recruiting has been considered in the past but rejected on financial grounds. It would require a formidable battery of medical officers and others to be 3 employed on a full time basis in rather tedious and $\propto$ repetitive work. It would also increase the throughput at $ᄋ$ APSC as the $6 \%$ that are medically rejected at ACIO level would then come forward to APSC for selection. It is therefore doubtful that this would present a significant improvement on the present system.

Finally, it should be remembered that basic training is the final and most important part of selection for service

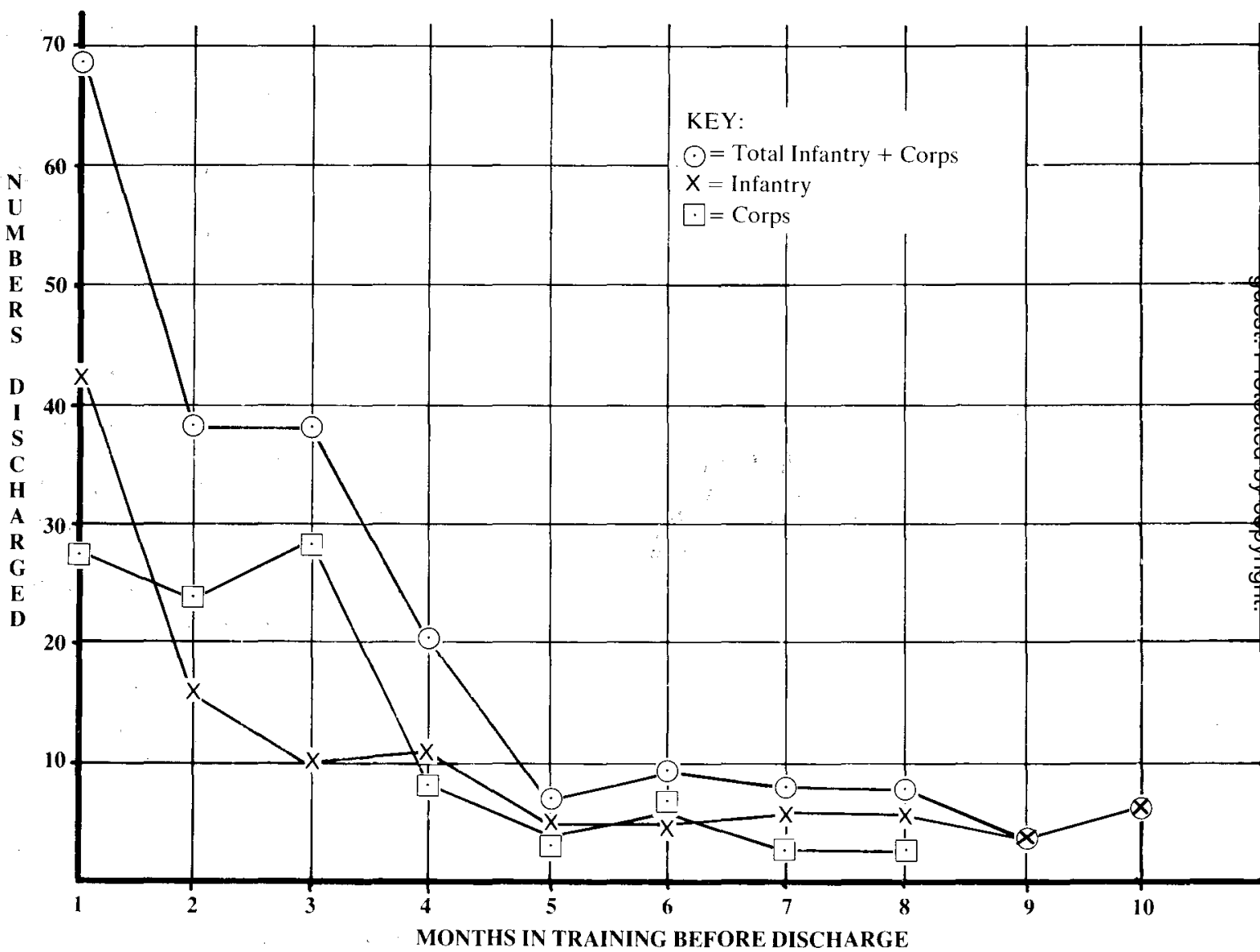

Fig 1. Time in Training before Discharge

Feedback should be provided to the ACIO doctors by notifying them of individuals that they have examined and who have subsequently been discharged on medical grounds. It may also be helpful for the APSC to produce a biannual report on medical discharges which could be circulated to ACIOs in order to try and heighten awareness of current problems. in the armed forces, and that it is only by testing recruits in training that various weaknesses will be exposed. By being too strict in applying medical standards and not allowing a potential recruit the opportunity of proving himself, many potential soldiers will be prevented from following their chosen career and the army will be denied their contributions. 


\section{Acknowledgements}

I am indebted to the Director of Army Recruiting, the Defence Medical Services, the staff of APSC, Stats M3 and all Manning and Records Offices for their help in preparing the figures for this study. I would also like to thank the Director of Army General Practice at the time of this study for his encouragement and assistance.

\section{REFERENCES}

1. ADAM K. and OSWALD I. Sleep helps healing, Br Med J 1984; 289: 1400 .

2. Wilson KCM, Evans-Smith E. and Oelman BJ. A study of patellofemoral pain in a junior training unit. $J R$ Army Med Corps 1983; 129: 1983.
Note from Defence Medical Services Directorate:

Several of the author's useful suggestions are now being put into practice. These include

1. PULHEEMS SYMPOSIA FOR ACIOs are held, $\stackrel{\mathbb{2}}{\Omega}$ not only at the RAM College Millbank, but in districts. 2. The District Symposia include discussions on the problems of recruits in training and demonstrations of the physical training a recruit has to undergo. 3. Among the speakers at Symposia are the Consultant Advisers in Ophthalmology, ENT and Orthopaedics. It is in these disciplines that conditions are very frequently the cause of discharge among recruits.

4. Audiometry is now carried out at ACIOs.

5. A new policy has been implemented in cases of $\tilde{\infty}$ Suspected Asthma, where ACIOs are now required to $\overrightarrow{0}$ refer Suspected cases to a Service consultant.

\section{RAMC RE-UNION IN MALTA}

Members of the Royal Army Medical Corps stationed in Malta during the Second World War are hoping to hold a re-union in Malta in the first fortnight of October next year.

The organizers are hoping to be joined by any men who served with any of the RAMC units during the war. Those interested are asked to contact:W Townsend, 57 Bennett Road, Ipswich, IP1 5HX, Suffolk, England. 